\title{
Segmentação hepática de Couinaud: além dos olhos do radiologista
}

\author{
Márcio Martins Machado*
}

Iniciamos nossos trabalhos em ultra-sonografia intra-operatória (USIO) em 1993. Desde então, realizamos, pessoalmente, 721 exames de USIO, com diversas indicações, seja para doenças hepáticas, biliares ou pancreáticas. Ao longo desse tempo, vimos também a evolução tecnológica apresentada pela ultra-sonografia (US) abdominal e pela tomografia computadorizada (TC). No campo da US abdominal vimos o surgimento de equipamentos mais modernos, melhorando a detecção das lesões, inclusive com o desenvolvimento da harmônica (e segunda harmônica), diminuindo os artefatos e corroborando ainda mais o aprimoramento da qualidade das imagens obtidas. De outra forma, em nosso país, tivemos ainda a utilização do Doppler no estudo das afecções abdominais. Em relação à TC, tivemos a passagem dos aparelhos convencionais para os helicoidais, e mais recentemente para os equipamentos com multidetectores.

Especificamente com relação ao fígado, víamos, na primeira metade da década de 90, uma grande discrepância entre as localizações das lesões referidas pelos exames pré-operatórios (US abdominal e TC) e aquelas evidenciadas durante a cirurgia, tendo como armamentário auxiliar na localização segmentar das lesões, a USIO. Pode ser considerado que a segmentação hepática poderia ainda não ter tão ampla divulgação, e que esses exames pré-operatórios ainda poderiam estar sendo realizados com equipamentos não tão modernos quanto os que dispomos hoje, especialmente em nosso meio. A análise da literatura internacional já demonstrava que autores estrangeiros já relatavam experiências consisten-

\footnotetext{
* Médico Radiologista do Hospital das Clínicas da Faculdade de Medicina da Universidade Federal de Goiás, Médico Radiologista Consultor do Departamento de Doenças do Aparelho Digestivo do Hospital Araújo Jorge (Hospital do Câncer) da Associação de Combate ao Câncer em Goiás, Chefe da Divisão de Radiologia Músculo-Esquelética e de Emergência do Centro de Diagnóstico do Hospital de Acidentados de Goiânia, Doutor em Radiologia pela Faculdade de Medicina da Universidade de São Paulo. E-mail: marciommachado@ibest.com.br
}

tes com relação a esta observação ${ }^{(1-3)}$, reiterando os mesmos achados por nós observados.

Analisando nossa experiência com a USIO após meados da década de 90 até os dias atuais, agora com os exames de US abdominal e de TC realizados com equipamentos modernos, inclusive com o uso da segunda harmônica e técnicas helicoidais de aquisição de imagens pela TC (inclusive com multidetectores), vimos ainda a persistência dessa discrepância entre a localização das lesões hepáticas segundo a segmentação de Couinaud ${ }^{(4)}$ e aquela observada durante as cirurgias e pela USIO. Este fato intrigante vem nos estimulando em nossos estudos sobre a aplicação da USIO na avaliação do fígado.

Durante a cirurgia, o "padrão ouro" para a localização das lesões somente poderia ser obtido com a realização de uma técnica invasiva proposta por Makuuchi $e t$ $a l{ }^{(5)}$. Segundo essa proposição, realizar-se-ia a punção seletiva de ramos portais e injetar-se-iam corantes para que se identificasse com precisão o segmento hepático suprido por aquele ramo portal, mediante a coloração deste setor do fígado pelo corante. Evidentemente, esta técnica não encontrou grande aplicabilidade fora do Japão, devido às dificuldades técnicas.

Mesmo considerando o exposto acima, o estadiamento cirúrgico complementado pela USIO representaria o método não-invasivo mais acurado para o posicionamento das lesões hepáticas segundo segmentos específicos, auxiliado pela própria ressecção e análise do espécime ressecado.

No campo da cirurgia, Makuuchi et al. ${ }^{(5-7)}$, no Japão, descreveram uma técnica revolucionária de ressecção hepática, chamada de subsegmentectomia sistemática hepática guiada pela USIO. Nessa nova técnica, seria realizada uma subsegmentectomia, o que permitiria a radicalidade oncológica, com preservação da maior quantidade possível de parênquima hepático. Nos pacientes cirróticos, com pequena reserva funcional hepática, essa 
preservação adquire importância fundamental. A USIO possibilitou a identificação de pequenos ramos da tríade portal (segmentares e subsegmentares), o que seria impossível ou muito difícil apenas com avaliação da superfície hepática, facilitando a realização dessa subsegmentectomia.

Nesse mesmo sentido, posteriormente, difundiu-se também a utilização da USIO para ressecção de metástases hepáticas de tumores colorretais. Atualmente considera-se que a margem de segurança acima de $1,0 \mathrm{~cm}$ seria adequada para a remoção dessas metástases ${ }^{(\mathbf{8 , 9 )}}$. Isto permitiria realizações de ressecções segmentares e subsegmentares, preservando o máximo de parênquima hepático residual, sem perder a radicalidade oncológica ${ }^{(8,9)}$.

O momento atual, então, representa uma situação em que a abordagem cirúrgica dos tumores hepáticos está refinada, com a possibilidade de ressecções segmentares e subsegmentares, em detrimento de hepatectomias clássicas, desde que existam limites anatômicos seguros para isto. Dessa forma, uma correta identificação das lesões nos segmentos hepáticos auxiliaria os cirurgiões no planejamento pré-operatório. Os radiologistas devem estar atentos é para o fato de que, com certa freqüência, ocorrem erros no posicionamento das lesões nos diferentes segmentos do fígado, conforme demonstrado por vários autores $^{(1-3,10)}$.

Fasel et al. ${ }^{(10)}$, estudando fígados de cadáveres frescos (com TC helicoidal), demonstraram que, para as porções craniais e caudais do fígado, $17,3 \%( \pm 6,5 \%)$ da área visualizada nas imagens axiais foram atribuídas a segmentos incorretos, comprovados pela correlação do exame meticuloso do espécime anatômico. Adicionalmente, para as porções centrais do fígado, este erro foi de 51,6\% ( $\pm 19,9 \%)$. Nelson et $_{\text {al. }}{ }^{(1)}$ também demonstraram que a localização (segmentar) de lesões hepáticas pela TC com arterioportografia diferiu daquela observada no momento da ressecção cirúrgica em 11 (31\%) dos 36 casos avaliados. Soyer et al. ${ }^{(2)}$ também observaram essa discrepância em oito (22\%) dos 36 casos estudados pela TC com arterioportografia.

Esses autores $^{(\mathbf{1 , 2})}$ e outros ${ }^{(3,10)}$ chamam a atenção para o fato de que os limites anatômicos indiretos, usados para localizar as lesões hepáticas na segmentação hepática em cortes axiais, não são completamente confiáveis e precisos, incorrendo em erros significativos. Referem que os limites anatômicos podem ser curvos, ondulados e eventualmente se interdigitando entre segmentos adjacentes, contribuindo para a dificuldade de uma perfeita localização.

Em nossa experiência com a realização de USIO durante ressecções hepáticas, em 127 casos de ressecções hepáticas avaliadas, os achados da TC helicoidal e da US abdominal (com relação à localização das lesões conforme a segmentação hepática de Couinaud) diferiram daqueles observados no momento da ressecção hepática (orientada pela USIO em todos os casos) em 44 (34,6\%) pacientes. Como pode ser notado, nossos dados são concordantes com aqueles da literatura, referidos anteriormente.

Todas essas informações devem servir de estímulo para os radiologistas, no sentido de procurar sempre um rigor máximo na identificação (pré-operatória) das lesões hepáticas com relação à segmentação hepática de Couinaud, na tentativa de que se diminua ao máximo o índice de erros. Este fato deve ser enfatizado, uma vez que os cirurgiões estão cada vez mais realizando ressecções hepáticas segmentares e subsegmentares, como pode ser compreendido do exposto acima. Nestes procedimentos, o correto posicionamento pré-operatório das lesões auxilia no planejamento pré-operatório, diminuindo a mudança de conduta cirúrgica que ocorre após a abertura da cavidade abdominal e realização da $\mathrm{USIO}^{(11)}$.

\section{REFERÊNCIAS}

1. Nelson RC, Chezmar JL,Sugarbaker PH, Murray DR, Bernardino ME Preoperative localization of focal liver lesions to specific liver segments utility of CT during arterial portography. Radiology 1990;176:89-94.

2. Soyer P, Roche A, Gad M, et al. Preoperative segmental localization of hepatic metastases: utility of three-dimensional CT during arterial portography. Radiology 1991;180:653-8.

3. Downey PR. Radiologic identification of liver segments (letter). AJR 1994;163:1267-8.

4. Couinaud C. Le foie, études anatomiques et chirurgicales. Paris: Masson, 1957.

5. Makuuchi M, Hasegawa H, Yamazaki S. Ultrasonically guided subsegmentectomy. Surg Gynecol Obstet 1985;161:346-50.

6. Makuuchi M, Yamazaki S, Hasegawa $H$. Ultrasonically guided liver surgery. Jpn J Ultrasound Med 1980;7:45-9.

7. Makuuchi M, Hasegawa H, Yamazaki S. Intraoperative ultrasonic examination for hepatectomy. Jpn J Clin Oncol 1981;11:367-90.

8. Way LW. Liver. In: Way LW, ed. Surgical diagnosis \& treatment. 10th ed. Connecticut: Appleton \& Lange, 1994:505-19.

9. Registry of Hepatic Metastases. Resection of the liver for colorectal carcinoma metastases: a multi-institutional study of indications for resection. Surgery $1988 ; 103: 278-88$.

10. Fasel JHD, Selle D, Evertsz CJG, Terrier F, Peitgen HO, Gailloud P. Segmental anatomy of the liver: poor correlation with CT. Radiology 1998;206:151-6.

11. Machado MM, Rosa ACF, Cerri GG. Ultra-sonografia intra-operatória (USIO). In: Cerri GG, Oliveira IRS, eds. Ultra-sonografia abdominal. Rio de Janeiro, RJ: Revinter, 2002:573-84 